\title{
Electronic traffic signs: reflecting upon its transition
}

\author{
Alberto Arbaiza Martín \\ Director Centro ESTRADA, Dirección General de Tráfico, Spain \\ Antonio Lucas-Alba \\ Associate Professor, Universidad de Zaragoza, Spain \\ Ana Hernando Mazón, Ma Teresa Blanch Micó \\ Research Technician, Universidad de Zaragoza, Spain
}

\begin{abstract}
In our days we face a fundamental issue concerning road signs. We may display contents in vertical and horizontal format (static signs, variable message signs, road markings), either on a post, a gantry or a dashboard. And we foresee a coming age where the excellent matrix resolution of painted signs will be truly approached by the resolution of full matrix displays. But we also risk a babel context threatening the universal approach encouraged by international catalogues as the 1968 Convention (ECE/TRANS/196, 2007). And the fundamental risk comes from our decisions regarding how the transition from the contents and formats displayed on static message signs to the ones displayed on electronic signs (in gantries or dashboards) should be. Our work explores this issue specifically, considering the transition from Advance Direction Signs (static message signs, class G, 1 in the 1968 Convention) to what could be termed Advance Location Signs (signs concerning the location of variable events with regards to certain landmarks) developed as an adaptation of the $\mathrm{G}, 1$ class to electronic traffic signs.
\end{abstract}

\section{SOME REMARKS CONCERNING THE USE OF ROAD SIGNS}

This paper deals specifically with complex road signs, i.e., road signs made of many elementary parts as pictograms, numbers, abbreviations or words. Compare (elementary) signs A (danger warning) or B (prohibitory) in the 1968 Convention, with (compound) signs G, 1 (advance direction signs), G, 14 (general speed limits) or G, 15 (road open or closed). Modern electronic road signage (e-signs), either in-car or VMS, may display both, assuming tactical and strategic functions to help road safety and mobility (Nenzi, 1997). But e-signs main raison d'être is fulfilling functions no other road signs could. That was the case from the very beginning when accidents, congestions, and the optimization of road infrastructures were targeted (e.g., EUCOCOST30, 1983). Locating variable events ahead, diversions and detours, strategic truck parking, or informing drivers about events going on in adjacent or near roads, are examples of complex functions e-signs may fulfil. But, how should these signs look like and why?

\subsection{Drivers decoding road signs: overview}

The first factor we should take into account is the end user. Elementary pieces of 
information (words, road signs, sounds, smells) can be learned, stored and at some point retrieved from Long Term Memory (LTM). Some road signs are arbitrary, learned as words (by convention) while other road signs are iconic and learned by virtue of their similarity to an external referent (Krampen, 1983). The fact is that elementary road signs seem to adopt certain organization in LTM and this would, for example, explain repetitive or semantic priming effects observed with road signs (Crundall \& Underwood, 2001).

Contrary to words and elementary road signs, sentences and complex road signs are complex information strings decoded on the fly, not retrieved as such from LTM. The average high school graduate knows about 45000 words, but by virtue of linguistic productivity he/she may utter or understand an infinite number of (grammatical) phrases (cf. Carroll, 2008). Complex, variable e-signs combine elementary pieces, but how? Some complex road signs form stacks similar to text strings, while others resemble maps or diagrams (Lay, 2004). The decoding mechanisms drivers put at stake depend on certain visual and structural cues made salient by the signs themselves.

\subsection{Taking old (posted) signs as templates for new e-signs}

We will focus on complex road signs displaying the qualitative location of variable events. Consider how to tell a foreign pedestrian where the post office is by giving him/her main landmarks as reference (e.g., red bridge, big oak tree; cf. Denis, 1997). Similarly, complex e-signs place variable events by reference to fixed landmarks (cities, nodes, bridges, etc.). The Consolidated Resolution on Road Signs and Signals (ECE/TRANS/212, 2010; Annex $\mathrm{X}$ ) recommends the 1968 Convention G, 1 signs to display direction, position or indication on VMS (Fig. 1). Hence, we will adopt the G, 1 class (Advance Direction Signs, ADS) as the main templates to follow when designing qualitative location of variable events (e.g., road works between City A and City B) for e-signs. We name them Advance Location Signs (ALS). Also the 1968 Convention may help us on the way forward (p. 51):

"Advance direction signs G, 1 may bear the symbols used on other signs informing road users of the characteristics of the route or of traffic conditions (for example: signs A, 2; A, 5; C, 3e; C, 6; E, 5a; F, 2).”

How may these templates be followed to ensure an optimal transition to ALS in particular?

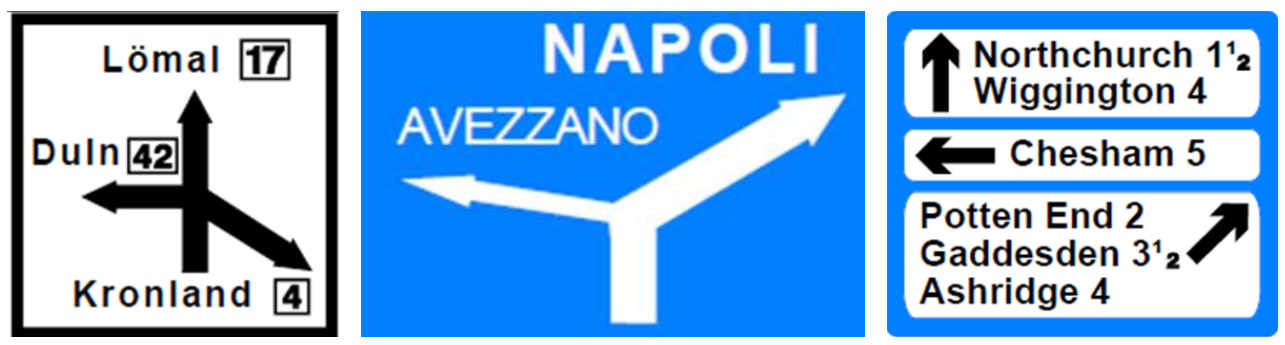

Fig. 1 - From left to right, signs G, 1 a, b and c in the 1968 Convention 


\subsection{The design matrix}

Clearly, the pain coat outperforms e-signs allowing for richer, nuanced and more sophisticated, yet visible, designs on a panel (Lay, 2004). Light and movement may help with conspicuity, and focusing attention, but as a matter of the information displayed by a road sign (message content) painted signs are highly functional and cost-effective. Consider Fig. 1, the signs are complex, design is not bad and their cost-effectiveness (e.g., the data-ink maximization principle; Tufte, 1990) is also good. From the point of view of the content complexity displayed, painted signs are better than electronic signs.

The most radical assumption for designing road signs ("you will paint there where is needed on the panel") was broken in the middle 1980s by hybrid VMS in most EU countries (Ellenberg \& Fabre, 1995). For a number of technical and economic reasons (Haitz \& Tsao, 2011), hybrid VMS split two zones, graphic (pictogram) and alphanumeric (text), downgrading these signs from international to local. Our experience on VMS harmonization, however, point to certain design strategies that can make some displays on hybrid VMS nearly or fully international (Arbaiza \& Lucas, 2012). On the other hand, the coming generation of full matrix VMS and in-car devices may reduce differences with paint coat by means of an improved LED surface. All in all, the design matrix available is a substantial issue when dealing with the transition from fixed signs to e-signs.

\section{DISPLAY MATRICES, ROAD SIGNS AND READING PROCESSES: THE AXIS OF E-SIGN TRANSITION}

\subsection{Reading road signs as text}

Fig. 1 shows three signs under one label, G, 1, that demand different reading and coding strategies from drivers. Signs G, 1c (stacked) are read following a (western) verbal strategy: from left to right and from top to bottom (Chan \& Bergen, 2005). In the direction indicated by the arrow-up (left) Northchurch (above) comes first, in 1.5 miles, and then comes Wiggington (below) in 4 miles. Some units are verbal (toponyms) and some are abstract (arrows). Note that although the elements on the message are understood making sense of juxtaposed units we need first to assign a meaning to each unit. A first step in the process of understanding a sentence is to assign elements of its surface structure to linguistic categories, a procedure known as parsing (Carroll, 2008). Parsing resembles problem solving in the sense that we are making decisions (not necessarily conscious) about where to place incoming words into the phrase marker we are building. The immediacy principle (Just \& Carpenter, 1980) suggests that we make these decisions as soon as we encounter a word: we see a word; we access its meaning from LTM, identify its likely referent and fit it into the syntactic structure of the sentence that we project, on the fly (cf. Carroll, 2008). I understand the set of elements on G, 1c as far as I come up with a likely syntactic structure where the elements fit in. The result is the meaning of that stacked complex sign. 
Drivers will enter this sentence-based decoding process as far as the road sign displayed resembles a stack of text. However, we aim to produce international e-sign complex messages -actually, non-word dependent. For example, we use pictograms (wind, congestion, snow-ice) not written nouns, and we substitute function words (prepositions, conjunction, and so on) using arrows instead. But function words are key elements on sentence structure and removing them may create ambiguity. Arrows are elementary graphic elements whose meaning varies in combination with adjacent or near elements (Kurata \& Egenhofer, 2005). The size and position of arrows may nuance essentially the meaning attached to elementary parts of the message (toponyms, numbers, abbreviations, and pictograms) when becoming inserted on a verbal structure with grammatical sense.

Coding verbal sentences is also difficult sometimes, as in the so-called garden-path sentences: when reading some complex sentences (e.g., with an embedded relative clause), the reader gets a first impression but may then detect some inconsistency and re-read the phrase assigning a sentence constituent to a different sentence node. There are more and less functional ways of combining the different elements together, or, there are dominant parsing strategies: e.g., the late closure strategy (when possible, we prefer to attach new items to the current constituent as it reduces working memory during parsing), or the minimal attachment strategy (we prefer attaching new items into the phrase marker being constructed using the fewest syntactic nodes consistent with the rules of language; Frazier, 1987; cf, Carroll, 2008). In sum, if ambiguous strings of elements are placed in a G, 1c type message the eventual meaning can be either too diverse or inconsistent.

\subsection{Reading road signs as diagrams}

Now compare G, 1c and G, 1b (Fig. 1). In the latter, below is near and above is far. We don't read the message bit by bit, but grasping a general sense of their map-like constituents. Here lies the key issue with diagram-like road signs: drivers know that the right strategy is not the most common one (reading text; a different one rules. If, as Jerome Bruner said, inference is going beyond the information given (cf. Tversky, 2005) what type of inference is required by $\mathrm{G}, 1 \mathrm{~b}$ ? It is tempting to say that it is understood as a structural analog (Johnson-Laird, 2006). Analogy is a complex type of similarity operating by an inductive reasoning (Holyoak, 2013). Analogical thinking involves some target (here, G, 1b) serving as a retrieval cue for a potential source analog (somewhere in LTM). It is then possible to establish a mapping -set of systematic correspondences that serve to align the elements of the source and the target. Understanding by analogy means that some sort of source analog should be available (e.g., a bird-view scheme of a road) in the drivers' LTM.

However, contrary to simple signs (congestion, wind) complex e-signs may have never been seen (e.g., Congestion between Madrid and Paris). Yet they can be represented and understood, yielding a mental model (Johnson-Laird, 2006). A possibility is that a source analog is then created to map the target (De la Fuente \& Minervino, 2008). Another possibility would concern a different reasoning operation: deduction based on visuospatial 
cues (Johnson-Laird, 2006). Here, the driver guesses what the elements displayed mean (e.g., a road map-like scheme, an arrow pointing upward, a city name) and drags a conclusion about the meaning of the whole (G1, b: "I should turn left"). This conclusion can only make sense, and be correct, considering that I want to go to Avezzano. But this very fact means that the deduction is made considering both the information outside and the knowledge in the driver's mind. This approach challenges the assumption that cognition is somehow separate from perception and motor control, a view known as embodied cognition (Markman, 2013). My understanding and deductive answer of G, 1b is supported by the fact that I expected to turn left at some point in my trip... to have lunch in Avezzano.

\section{COMPLEX E-SIGNS TRANSITION AND THEIR INTERACTION}

The main parameters intervening in the design of complex e-signs shown interesting parallelisms with verbal language: the elementary parts of verbal utterances, words, are retrieved from LTM, but sentences (both for speaking and understanding, for writing and reading) are structured and compound on the fly. Another source of similarity is synonyms. However, by virtue of Article 3 on the 1968 Convention (Obligations of the Contracting Parties, p. 6):
"Where this Convention prescribes a sign, convention or marking for signifying a certain rule or conveying certain information to road users, the Contracting Parties undertake (...) not to use any other sign, symbol or marking for signifying that rule or conveying that information."

Very few elementary symbols in the 1968 Convention have a double or alternative format (e.g., A, 12a and b, both for pedestrian crossing). But Fig. 1 and the aforementioned note on page 51 of the 1968 Convention show two alternative ways of producing complex road signs. What we have tried to underline here, with regards to the coming e-signs, is the complex interplay between the design matrix (the G, 1 model used as template to elaborate ALS) and the specific cognitive processes that drivers put at stake when reading different road signs. We still understand fixed signs $G, 1 b$ and $G, 1 c$ in spite of them calling for different cognitive mechanisms (let's say, stack versus diagram), but the resulting e-signs can be somehow confusing themselves or in combination with "synonyms" made after a differing template (Fig. 2). In this virtual, patchwork scenario the posted sign is a standard stack sign (perhaps not the right one for motorways). But the design is presumably adequate to indicate drivers that they are in the right direction towards Northchurch and Wiggington. The hybrid VMS relies on a standard model (pictogram on the left, three lines of text with an average of 15 characters per line). This is a standard VMS in many countries in Europe. It seems to indicate, by means of a verbal reading scheme, that there is congestion between Northchurch (coming first) and Wiggington. Recent data indicate that more than $70 \%$ of UE drivers understand this sign (EIP, 2015). Last, the in-car display adopts a diagrammatic sign indicating congestion between Northchurch (coming first, so 
below) and Wiggington (coming later, above). The arrow in the posted sign comes up; the arrow in the VMS comes down; the road depicted in the in-car display points forward. All messages are international ones, relying on official (R.E.2) symbols and toponyms.

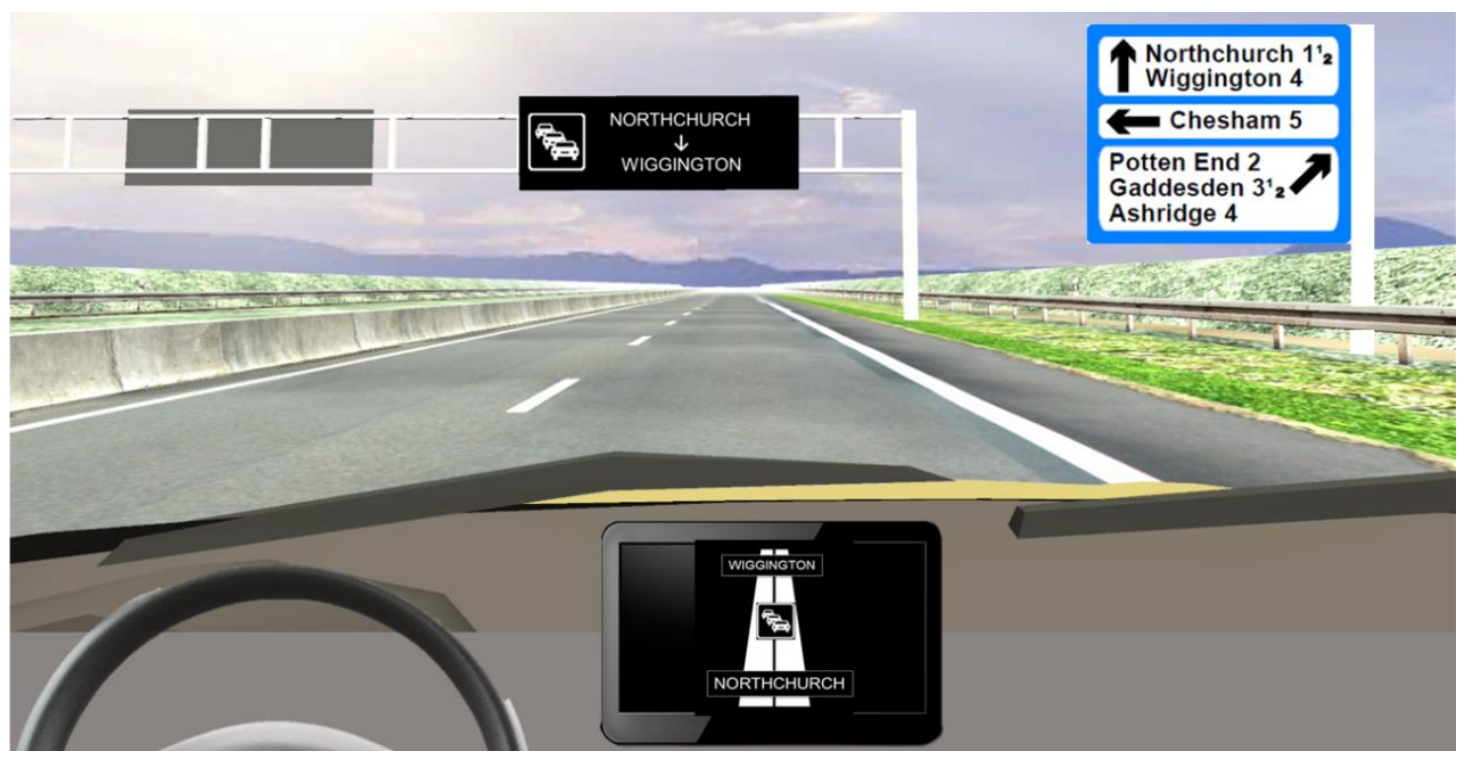

Fig. 2 - Simultaneous display of possible posted, in-car and hybrid VMS signs (I)

Now, Fig. 3 shows an alternative virtual scenario, showing a complementary combination and display of road signs that follow the $\mathrm{G}, 1 \mathrm{~b}$ or $\mathrm{G}, 1 \mathrm{c}$ templates.

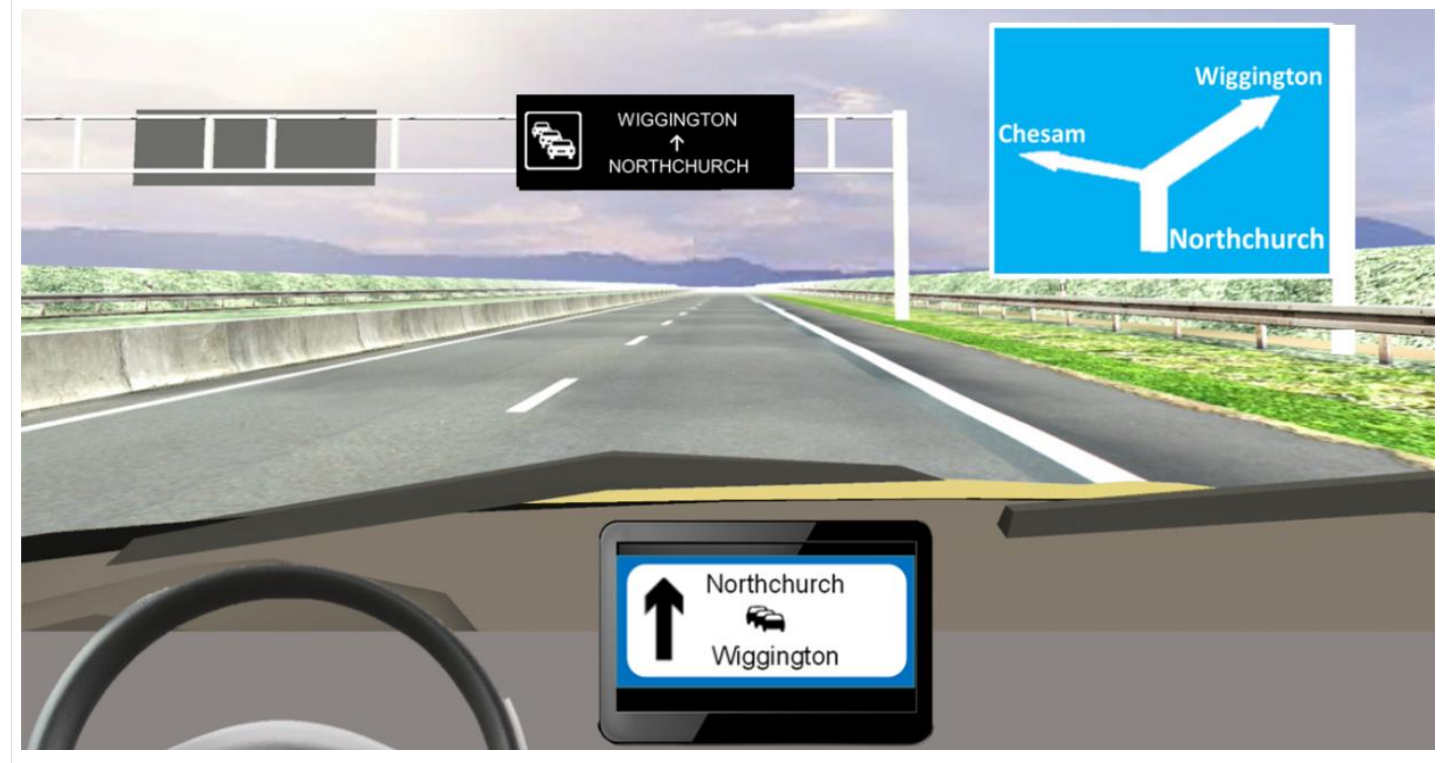

Fig. 3 - Simultaneous display of possible posted, in-car and hybrid VMS signs (II)

The posted sign is a diagrammatic sign $(G, 1 b)$. The design is in principle adequate to indicate drivers that they are in the right way to Northchurch, and Wiggington or Chesham. The hybrid VMS relies on the standard model indicating that there is congestion between Northchurch (below) and Wiggington (above). Recent data indicate also that around $70 \%$ of UE drivers understand this sign (EIP 2015, Deliverable 1). Last, the in-car display 
adopts a stack, verbal pattern indicating that a congestion lies between Northchurch (coming first, so above) and Wiggington (coming later, below) according to G, 1c. The arrow in the posted sign comes up and it is a topological representation of the road; the arrow in the VMS also comes up; the arrow displayed in the in car display points up, but it does not represent a road where the toponyms are located (only direction: Northchurch comes first). Again, all messages are international ones, relying on official (R.E.2) symbols and toponyms. But, could we make it easier for drivers?

\section{CONCLUDING REMARKS}

This paper aims to describe the current context regarding e-signs, their relationship with fixed signs, the possibilities offered by the matrix displays, and the mechanisms and cognitive processes entailed by the different templates. The aim of this work is fostering our reflection about the possible ways forward. Firstly, modern signs also bring on modern problems. The 1968 Convention solves some of the problems in Fig. 2 and Fig. 3 asking Contracting Parties for coherence (e.g., use the diamond or the triangle for danger warning signs, but not both). But present and coming e-signs present certain challenges to coherence. Hybrid VMS restrict depicting possibilities. Full matrix displays, particularly on board, seem to rule their own criteria (e.g., ISO/TS 19321, 2015). But road signs still form a whole of information for drivers. Could car displays adapt to national preferences if I trip in different countries (e.g., in Italy vs United Kingdom)? Or should they keep personal driver preferences even if clashing with other signs, posted or electronic, around? May drivers' cognitive reading habits be a source of inattention with consequences for safety and mobility? Coming e-signs are a potential source of improvement for modern traffic. But e-signs are also sophisticated tools, both in the mind of drivers and in the hands of road operators, we need to understand better.

\section{AKNOWLEDGEMENTS}

Some of the ideas presented by this paper where exposed in the $5^{\text {th }}$ meeting of the Expert Group on Road Signs and Signals (UNECE) in November 2015. We thank Monica Pronin (Amazing Designs) and Robert Nowak (WP.1 Secretariat) for their kind suggestions for improvement. This paper has been written with the support of the Direccion General de Tráfico, Spain, under grant SPIP2014-01345: Análisis de las claves de desarrollo de los criterios de diseño de la señalización variable teniendo en cuenta el factor de su internacionalización, presente y futura.

\section{REFERENCES}

ARBAIZA, A., LUCAS, A. (Coords.) (2012). VMS-DG01. Principles of VMS Message Design. Version 2.0, December 2012. http://www.easyway-its.eu/

CARROLL, D.W. (2008). Psychology of Language. Belmont: Thomson.

CHAN, T.T., BERGEN, B. (2005). Writing direction influences spatial cognition. In B. Bara, L. Barsalou and M. Bucciarelli (Eds.). Proceedings of the $27^{\text {th }}$ Annual Conference of 
the Cognitive Science Society Mahwah, NJ: Erlbaum, 412-417.

CRUNDALL, D., UNDERWOOD, G. (2001). The priming function of road signs. Transportation Research Part F, 4, 187-200.

DE LA FUENTE, J., MINERVINO, R. (2008). Pensamiento analógico. In M. Carretero, M. Asensio (Coord.). Psicología del pensamiento. Madrid: Alianza Editorial, 247-268.

DENIS, M. (1997) The description of routes: a cognitive approach to the production of spatial discourse. Current Psychology of Cognition, 16 (4), 409-458.

ECE/TRANS/196 (2007). Convention on Road Signs and Signals of 1968. United Nations: New York and Geneva.

ECE/TRANS/212 (2010). Consolidated Resolution on Road Signs and Signals (R.E.2). http://www.unece.org/trans/roadsafe/rsrec.html

EIP (2015). Evaluation of the use of the procedures and knowledge developed for VMS harmonization in concrete applications. Deliverable 1. SA4.2 VMS Harmonization. European ITS Platform. https://www.easyway-its.eu/

ELLENBERG, M., FABRE, P. (1995). Melyssa Corridor. Mediterranean Lyon-Sttutgart Site for ATT. Transport Telematics Project V2040. D10. Commission of the European Communities - R\&D Programme Telematics Systems in the Area of Transport (DRIVE II). EUCO-COST 30 (1983). European project on electronic traffic aids on major roads. Final Report (EUR 7154). Luxembourg: Commission of the European Communities.

HAITZ, R., TSAO, J.Y. (2011). Solid-state lighting: 'The case' 10 years after and future prospects. Physica Status Solidi A 208, No. 1, 17-29.

HOLYOAK, K.G. (2013). Analogy and Relational Reasoning. In Holyoak, K.J., Morrison, R.G. (2013). The Oxford Handbook of Thinking and Reasoning. Oxford University Press, 234-259.

ISO/TS 19321 (2015). Intelligent transport systems -Cooperative ITS - Dictionary of invehicle information (IVI) data structures.

JOHNSON-LAIRD, P. N. (2006). How we reason. New York: Oxford University Press.

KRAMPEN, M. (1983). Icons of the road. Semiotica, 43 (1/2), 1-203.

KURATA, Y., EGENHOFER, M. (2005). Structure and Semantics of Arrow Diagrams. COSIT '05, September 2005, Ellicottville, NY.

LAY, M.G. (2004). Design of traffic signs. In C. Castro and T. Horberry (Eds.): The Human Factors of Transport Signs, CRC Press, Boca Raton, 25-48.

MARKMAN, A.B. (2013) Knowledge Representation. In K.J. Holyoak, R.G. Morrison (Eds.) The Oxford Handbook of Thinking and Reasoning, Oxford University Press, 36-51.

NENZI, R. (1997). Use of Dynamic Signing (VMS). Volume 3C. Telematics on the Trans European road Network 2 - TELTEN2. Final Report, Brussels: ERTICO.

TUFTE, E.R. (1990). Envisioning information. Chesire C.T.: Graphics Press.

TVERSKY, B. (2005). Visuospatial reasoning. In K.J. Holyoak y R.G. Morrison (Eds.). The Cambridge Handbook of Thinking and Reasoning, Cambridge: Cambridge University Press, 209-240. 